\begin{tabular}{|l|l|}
\hline $\begin{array}{l}\text { Las primeras aproximaciones de la política exterior de Brasil en África y la utilización } \\
\text { de las prácticas culturales de la población negra brasileña }\end{array}$ & Titulo \\
\hline Velasco Molina, Mónica - Autor/a; & Autor(es) \\
\hline $\begin{array}{l}\text { De Raíz Diversa. Revista Especializada en Estudios Latinoamericanos (Vol. 1 no. 2 } \\
\text { oct-dic 2014) }\end{array}$ & En: \\
\hline México D.F. & Lugar \\
\hline $\begin{array}{l}\text { Programa de Posgrado en Estudios Latinoamericanos, Universidad Nacional } \\
\text { Autónoma de México }\end{array}$ & Editorial/Editor \\
\hline 2014 & Fecha \\
\hline & Colección \\
\hline Prácticas culturales; Política exterior; Afro-brasileños; Brasil; América Latina; África; & Temas \\
\hline Artículo & Tipo de documento \\
\hline "htp://biblioteca.clacso.edu.ar/Mexico/ppel-unam/20160614052803/Nelasco.pdf" & URL \\
\hline $\begin{array}{l}\text { Reconocimiento-No Comercial-Sin Derivadas CC BY-NC-ND } \\
\text { http://creativecommons.org/licenses/by-nc-nd/2.0/deed.es }\end{array}$ & Licencia \\
\hline
\end{tabular}

Segui buscando en la Red de Bibliotecas Virtuales de CLACSO http://biblioteca.clacso.edu.ar

Consejo Latinoamericano de Ciencias Sociales (CLACSO)

Conselho Latino-americano de Ciências Sociais (CLACSO)

Latin American Council of Social Sciences (CLACSO)

www.clacso.edu.ar

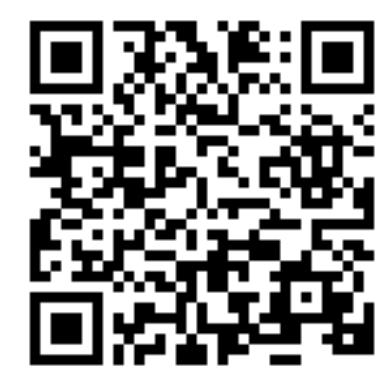




\section{Las primeras aproximaciones de la política exterior de Brasil en África y la utilización de las prácticas culturales de la población negra brasileña}

Mónica Velasco Molina*

Resumen. Después de la abolición de la esclavitud, el prejuicio y la exclusión en contra de la población de descendencia negra formaron parte de la cotidianidad en Brasil. Sin embargo, la imagen del país como un paraíso racial fue alentada, sostenida y divulgada por la élite en el poder, especialmente a partir de la década de los años sesenta, momento que coincidió con el inicio del proceso de la descolonización africana. Una élite que al mismo tiempo que segregaba y discriminaba a los descendientes de los negros brasileños al interior del país, comenzó a "exhibir" y mostrarse orgullosa, a escala internacional, de su población negra. El artículo pretende mostrar cómo la élite, sobre todo en la época de la dictadura militar, buscó apropiarse de los elementos culturales más representativos del grupo racializado con objetivos de política exterior, pero sin modificar las estructuras sociales que mantenían parámetros de discriminación y desigualdad. Sin embargo, esto no ocurrió sin la movilización del grupo directamente afectado, incluso en momentos en los que la represión azotó a la sociedad brasileña.

Palabras Clave: Brasil, África, Política exterior, Afrobrasileños.

Abstract. After the abolition of slavery, prejudice and exclusion against the afro-descendant people were part of everyday life in Brazil. However, the power elite encouraged and disseminated the image of a country with a racial paradise, especially since the decade of the sixties, which coincided with the decolonization process in Africa. So, the elite began "exhibiting" and showing pride in its black population at the international level, while maintaining the segregation and discrimination of the descendants of black Brazilians within the country. This article shows that the elite, during the sixties, especially during the military dictatorship, sought to appropriate the most representative cultural elements of this racialized group for foreign policy objectives, without modifying the structures that maintained social discrimination and inequality. Though, this was not without the mobilization of the affected group, even in times when the repression struck Brazilian society.

KeYwords: Brazil, Africa, Foreign Policy, Afro-Brazilian.

Recibido: 02 de agosto de 2014. Aceptado: 15 de septiembre de 2014.

Doctora en Estudios Latinoamericanos, UNAM. <monvelmol@yahoo.com.mx> 


\section{INTRODUCCIÓN}

$\mathrm{C}$ uando Getulio Vargas asumió el poder en Brasil en 1930, tenía frente a sí, entre otros asuntos, la necesidad de formar y consolidar el nacionalismo brasileño. Los arraigados regionalismos aún a principios del siglo $\mathrm{xx}$, colocaban en peligro la unidad territorial del país, por lo que era menester crear un nacionalismo capaz de enfrentarse a las divisiones en el país. Pero Vargas también comprendía que más allá del peligro separatista que hacía urgente fortalecer la identidad del brasileño, lo era el hecho de legitimar un proyecto de nación moderno y que se diferenciara del resto de las naciones. Si a finales del siglo xix un importante sector de la élite brasileña tuvo como premisa las teorías raciales y, en consecuencia, formar un país blanco y europeizado por medio de múltiples proyectos de inmigración, a partir de los años treinta del siglo xx, el eje fue modificado con el objetivo de apuntalar un nacionalismo brasileño que abarcara un amplio sector de la población. Para alcanzar dicha iniciativa, el Estado fundó diversos órganos gubernamentales, tal fue el caso del Servicio Patrimonio Histórico y Artístico Nacional (sphan), el Servicio Nacional de Teatro (sNT), el Instituto Nacional del Libro, así como el Instituto Nacional del Cine Educativo (INCE) (Lippi, 2008: 105).

Fue en esa coyuntura histórica que el mestizo cobró sentido como la encarnación de la brasilidad. Nacionalidad y mestizaje, ${ }^{1}$ fuertemente entrelazados. Por ello, la obra de Gilberto Freyre en general, pero en especial, su Casa Grande \& Senzala, ${ }^{2}$ cobró gran relevancia y sentido dentro del debate del ser brasileño. Obra en la que discierne en torno de la relación y la aproximación entre los tres diferentes grupos que conformaron el Brasil colonial: portugués, indígena y negro; donde, contrario a las ideas de las teorías raciales, la exaltación al mestizaje y su énfasis en que el problema de Brasil no era la raza, sino las condiciones económicas y las desigualdades sociales. Así, Freyre perfiló su idea acerca de una nueva forma de pensar la identidad del brasileño. Por lo tanto, la imagen de la

\footnotetext{
${ }^{1}$ Mestizaje entendido no sólo como cruzamiento físico entre diversos grupos étnicos, sino especialmente su interrelación e interpenetración en los diversos ámbitos de la cultura.

${ }^{2}$ Es importante recordar que la obra de Casa Grande \& Senzala se inserta en la trilogía Sobrados \& Mucambos y Ordem \& Progresso, que permite, como el propio autor menciona, "la comprensión y la interpretación del Hombre a través de un análisis del pasado y del ethos de la gente brasileña" en "Como e porque escrevi Casa Grande \& Senzala" (Giucci, 2002: 709).
} 
cordialidad entre los diferentes grupos que dieron la génesis del brasileño iba más allá de la simple idea de fraternización. Era la corporificación del ser brasileño. ${ }^{3}$

Es importante resaltar que Freyre siempre se refirió a una democracia social $^{4}$ y no racial, lo que marca una notable diferencia. Él no se refirió a una cuestión de derechos y deberes ciudadanos, y por consecuencia, a una igualdad jurídica, sino a una cuestión de mestizaje que va más allá del matrimonio o de asumir un compromiso legal; es la relación sexual y de relacionamiento corporal que, debido a ese constante interrelacionamiento, deriva en un mestizaje cultural.

En ese tenor de ideas, la noción de democracia racial sobrepasó las fronteras brasileñas mediante el concepto de lusotropicalismo, formulado también por Gilberto Freyre, en especial en su obra $O$ Luso e o trópico (1962). Tal noción se refería a la experiencia que de la colonización portuguesa se gestó en América, Asia y África, y de la cual surgió una "civilización luso-tropical", caracterizada por el mestizaje, por ser más una colonización cristocéntrica ${ }^{5}$ que etnocéntrica, por la rápida adaptación del portugués a los territorios colonizados, por la función que la mujer guardaba en su tarea colonizadora y por su carácter misionario y civilizador (Campos de Moraes, 2001: 36-37).

${ }^{3}$ Es importante recordar que la primera edición de Casa Grande \& Senzala fue publicada por la editora Olympo, propiedad de José Olympo, amigo de Lourival Fontes (Director del DIP). Dicha editorial abrió espacios para que autores brasileños publicaran sus investigaciones. No por casualidad, dicha casa editorial también publicó Raizes do Brasil de Sérgio Buarque de Holanda, Evolução política do Brasil de Caio Prado Jr; es decir, Olympo imprimió las tres grandes obras que, como mencionó António Cândido, fueron los ensayos más importantes de interpretación de Brasil y que hasta hoy constituyen un punto de referencia para la comprensión del ser brasileño. También en esa editorial fue publicado Jubiabá (octubre de 1935) de Jorge Amado y Vidas Secas de Graciliano Ramos, brindándoles una enorme proyección internacional.

${ }^{4}$ Interesante el testimonio que utilizó Freyre del reverendo James C. Fletcher, quien comparó en 1879 a la todavía monarquía brasileña con EUA, en el sentido de que la Constitución brasileña no hacía diferencia entre color o raza ni directa ni indirectamente como base para sus derechos civiles. El reverendo también remarcó que cualquiera podía alcanzar un alto grado en la sociedad si se contaba con la libertad, dinero y mérito. De ahí que todos tuvieran oportunidades para el ascenso social. Resaltando que en Brasil, como todos los pueblos latinos, se inclinaba más por el mérito que por el color (Freyre, 2004: 531).

${ }^{5}$ Para Freyre, los portugueses habían practicado un cristianismo más apegado al franciscano; es decir, más humilde y con más respeto al prójimo como igual (Campos de Moraes Leme, 2001: 38). 
Por lo que el lusotropicalismo también fue un elemento importante y defendido por el gobierno de Salazar al insuflarle vida al colonialismo portugués. Uno que, para la época, estaba en entredicho al encontrarse en decadencia su justificación de la superioridad e inferioridad de las razas. De tal forma que tanto el gobierno luso como el brasileño se beneficiaron de extender por el mundo que uno era el modelo de éxito de la colonización portuguesa, ufanándose de su cordialidad entre las razas; el otro, negando su torpeza como agente colonizador para extender el desarrollo y el progreso, gestando una obra colonial que resultaba benigna y hasta positiva.

Sin embargo, a pesar del peso que para la política exterior de Brasil y Portugal tuvo la idea de la democracia racial, ésta ya se encontraba seriamente cuestionada desde la década de los años cincuenta no sólo por los líderes negros brasileños como por la propia Unesco. Fue al término de la Segunda Guerra Mundial, cuando dentro del mencionado organismo internacional, surgió la preocupación por entender cómo era posible alcanzar una sociedad multiétnica que conviviera armónicamente. Dado que la guerra había demostrado las consecuencias que podía desencadenar un racismo extremo, los especialistas de dicho foro tomaron la determinación de emprender un análisis de los diferentes factores económicos, políticos, sociales, culturales, y psicológicos que "influían en el sentido de armonía o desarmonía en las relaciones de raza” (Pinto, 1998: 13). La elección fue clara, Brasil era el modelo que se contraponía a lo que ocurría en países como, por ejemplo, Estados Unidos de América.

De tal manera que Alfred Métraux, como representante del Programa sobre Tensiones Sociales del Departamento de Ciencias Sociales de la Unesco, encabezó un grupo de sociólogos para profundizar en las relaciones raciales en Brasil.

Florestan Fernandes y Roger Bastide con su trabajo en São Paulo, ${ }^{6}$ se sumaron al equipo que Métraux comenzó a reunir. A él también se adhirieron Thales de Azevedo para llevar a cabo sus estudios acerca de Bahia que derivó en el trabajo Les élites de couleur dans une ville brésillienne, Costa Pinto con O negro no Rio de Janeiro y Charles Wagley con Race and class in rural Brazil, focalizándolo en Recife.

${ }^{6}$ Desde la escuela de sociología de la Universidad de São Paulo (USP), comenzaron a levantarse voces críticas uniéndose a las diversas investigaciones de Florestan Fernandes. Los trabajos de Octavio Ianni y Fernando Henrique Cardoso son ejemplo de ello. 
Las investigaciones representaron una magnífica oportunidad para contrastar el discurso con la realidad, distanciándose de las investigaciones que percibían al negro como un elemento únicamente cultural, para entenderlo en su dimensión de sujeto que luchaba por incorporarse a la sociedad en sus múltiples dimensiones. ${ }^{7}$ Además, para esa época, las figuras de Gilberto Freyre, así como Arthur Ramos, eran reconocidas en el mundo, generando en el imaginario de la intelectualidad internacional la identificación entre Brasil y el discurso de la democracia racial.

Sin embargo, contrario a lo esperado, los estudios elaborados desmintieron abiertamente la idea de la democracia racial, evaporándose los argumentos acerca del supuesto paraíso racial brasileño. A pesar de que las investigaciones demostraron el racismo del que eran sujetos los descendientes de los negros en Brasil, no por ello se piense que la imagen de un Brasil donde prevalecía la cordialidad entre blancos y negros desapareció instantáneamente. Esto no ocurrió, no sólo porque la imagen era ampliamente difundida, sino porque además, el Estado procuró mantenerla el mayor tiempo posible. Valiéndose de las diversas herramientas que tuvo a su alcance, como será demostrado durante las siguientes líneas, incorporó las ricas aportaciones culturales de los negros al patrimonio nacional y, aprovechando su posición de interlocutor con la Comunidad Internacional, las utilizó para incluirlas en su discurso de política exterior para aproximarse a los nacientes países africanos.

Por lo tanto, la idea de la democracia racial debe ser entendida en el tiempo y en el espacio. Ésta logró reconfigurarse y tomar vida de acuerdo a los intereses que el poder político brasileño, o portugués, deseaba alcanzar.

Teniendo esto en mente, es necesario recordar que las relaciones oficiales entre África y Brasil se habían "enfriado" con la abolición del tráfico esclavista y porque África, después de la Conferencia de Berlín (del 15 de noviembre de 1884 al 26 de noviembre de 1885), pasó a ser dominio de las potencias en turno, pero también por el esfuerzo de la diplomacia brasileña en tratar de "olvidar" su pasado de raíces africanas con el propósito de construir una nación blanca bajo los parámetros europeos. En este sentido, cabe

7 Es importante resaltar que los trabajos presentados en el "Primer Congreso Brasileño del Negro" organizado por el Teatro Experimental Negro, llevado a cabo en agosto de 1950, fueron una gran referencia para los investigadores que se engallaron en dicha tarea. Dicho Congreso convocó a un número significativo de especialistas de diversas disciplinas y países. (Quilombo, 1950: 3). 
recordar que José Maria da Silva Paranhos Jr. (mejor conocido como el Barón de Rio Branco), como Ministro de Relaciones Exteriores, hizo todo lo que se encontró a su alcance para colocar barreras que impidieran el ascenso de los negros en el Servicio Exterior Brasileño, hecho que denunció en su momento, entre otros, Haroldo Costa en 1948, en su artículo "Queremos estudar", en el periódico Quilombo, ${ }^{8}$ así como Gilberto Freyre en su obra Ordem \& Progresso de 1957.

La relación con África, entonces, era de distanciamiento. Por lo que no extraña que durante el segundo mandato de Getulio Vargas, África fuera concebida sólo en términos de expansión comercial y sin mostrar ningún apoyo en el proceso de descolonización africana (Teles dos Santos, 2005: 30). En realidad, en aquella época, la política exterior brasileña estaba alineada a los objetivos marcados por Estados Unidos de América, por lo que África no era el centro de atención del Itamaraty ni tampoco de la Marina brasileña. Las relaciones estaban en una fase de estancamiento, siendo Brasil el más perjudicado de ese alejamiento, pues le impidió desarrollar sus fuerzas navales y mercantes. Debido a esto perdió su dimensión oceánica en relación con el exterior, generando un claro "vacío de poder" hacia el Atlántico Sur (Alves, 2011: 62).

\section{EL COMIENZO DE UN CAMBIO EN LAS RELACIONES ENTRE BRASIL Y ÁFRICA}

Las relaciones entre Brasil y África comenzaron a dar un giro durante la última etapa del mandato del presidente Juscelino Kubitschek (1956-1960). Esta modificación se debió, no sólo a una decisión unilateral del gobierno brasileño, sino también a dos factores más: el primero, la ola de descolonización que después de la Segunda Guerra Mundial comenzó a gestarse en una primera etapa en Asia y que después se extendió al continente africano.

El segundo, consecuencia del primero, fue el impulso que los movimientos negros que comenzaron a darle al tema sobre la descolonización, al tiempo que cada vez se organizaban más actos que les brindaban mayor

${ }^{8}$ Haroldo Costa, en su artículo "Queremos estudar" (Quilombo, 1948: 4), señaló esto de la siguiente forma: "Nadie desconoce los tremendos obstáculos que encuentra el joven negro cuando se inscribe para presentar examen al Instituto Rio Branco (Ministerio de Relaciones Exteriores); o el examen de admisión a las escuelas militares superiores. Actualmente ya existen cadetes de color, sin embargo puedo asegurar que conseguirán ser admitidos después de inauditos sacrificios." 
visibilidad, aunque en ocasiones fueron duramente criticados por los periódicos de la época. ${ }^{9}$

A pesar de este giro en las relaciones Brasil-África impulsado por Kubitschek, no existe la menor duda que fue durante el breve gobierno de Jânio Quadros (1/02/1960-25/08/1960) cuando se desarrolló la nueva perspectiva que Brasil le concedió no sólo al continente africano como a una nueva proyección de su política exterior. De hecho, este viraje fue percibido desde su primer discurso como Presidente, el 31 de enero de 1961.

Durante su alocución fue clara su intención de practicar durante su mandato una política exterior soberana, de ahí que criticó y se distanció del colonialismo europeo que Brasil apoyaba desde 1942, así como brindar su respaldo a los jóvenes países que nacían a la vida independiente. Quadros fue claro al señalar: "A Brasil le corresponde extender las manos a ese mundo joven, comprendiéndole los excesos o desvíos ocasionales [...] Comprender significa auxiliar en lo que sea posible y en lo que sea necesario" (Costa, 2007: I, 30). Con estas palabras, Quadros amplió el espectro y la libertad de acción de las relaciones internacionales de Brasil, atreviéndose a dejar de lado el viejo discurso que se ceñía a las relaciones de bipolaridad para en su lugar posicionar a Brasil como un país que deseaba abrirse al mundo con independencia de su comunión político-filosófica.

Pero también en aquel discurso, Quadros hizo una referencia interesante respecto a Brasil, caracterizándolo como un país "impermeable al prejuicio de raza, de color, de credo, que realizó el milagro de su unidad cimentada en los siglos y que comienza a erigir una civilización sin rival en estos paralelos" (Costa, 2007: I, 30).

Esta declaración resulta interesante, pues el Presidente, sin mencionar literalmente "democracia racial" hizo referencia a las buenas relaciones sociales que supuestamente regían en la sociedad brasileña. Dicha afirmación fue reafirmada por el recién nombrado Ministro de Relaciones

\footnotetext{
${ }^{9}$ Un ejemplo fue el concurso de artes plásticas del Cristo Negro, que tuvo gran aceptación entre los artistas e incluso fue respaldada por el cardenal Jaime Câmara y el obispo Hélder Câmara. Sin embargo, una colaboradora del periódico Jornal do Brasil, el 26 de junio de 1955, acusó esta actividad como "altamente subversiva", donde estaba presente la blasfemia y el mal gusto. Denunciando que sólo la idea de un Cristo de color era en sí misma capciosa. Además, solicitó a las autoridades eclesiásticas impedir que se llevara a cabo "ese atentado a la Religión y a las Artes". Alice Linhares Uruguay, "Cristo Negro" (Jornal do Brasil, 1955: 2).
} 
Exteriores Afonso Arinos de Melo Franco, quien en su discurso de "posse" declaró:

un pueblo democrático y cristiano, cuya cultura latina se enriqueció con la presencia de influencias autóctonas, africanas y asiáticas [siendo] étnicamente mestizos y culturalmente mezclados de elementos provenientes de las inmensas áreas geográficas que en este siglo se abrieron a la vida internacional. Además de ello, los procesos de mestizaje con que la metrópoli portuguesa nos plasmó facilitaron nuestra democracia racial, que, si no es perfecta como desearíamos, es, con todo, la más avanzada del mundo. No tenemos prejuicio contra las razas coloridas, como ocurre en tantos pueblos blancos o predominantemente blancos; ni prejuicio contra los blancos, como ocurre con los pueblos predominantemente de color. ${ }^{10}$

Sus palabras son muy relevantes en el sentido de que, por un lado, refrenda la idea del Lusotropicalismo y del mestizaje, reivindicando positivamente a Portugal como colonizador; por otro, respalda pública y abiertamente la idea de que existe una democracia racial en el país a pesar de ser él quien en los años cincuenta como diputado presentó el Proyecto de Ley 562, el 17 de julio de 1950, y aprobado en 1954, que castigaba penalmente la práctica de racismo.

De tal manera, que tanto la declaración del presidente Quadros como la de su ministro de relaciones exteriores, Afonso Arinos, tuvieron la intención de tender desde ese primer momento, un puente entre la diplomacia brasileña y los recién independientes países africanos con el propósito de ser el enlace entre ellos y la parte occidental, evitando que aquellos fueran influidos por el bloque socialista. De ahí que la connotación de democracia cobrara tanta relevancia en un doble sentido, tanto racial como político.

Pero si reunimos las variables democracia racial, economía y pragmatismo en la política exterior, el resultado es que Brasil deseaba ampliar su mercado hacia los jóvenes países africanos valiéndose de sus raíces étnicas y culturales, pero especialmente de la tan vanagloriada democracia racial. En tiempos de la Guerra Fría, además, se colocaba como el alfil que garantizaría a los países occidentales cuidar de los africanos de la influencia comunista. Por lo tanto, Brasil tenía ante sí la posibilidad de proyectarse como una potencia, donde África funcionaría como su más importante

10 Discurso de posse do Ministro das Relações Exteriores, Afonso Arinos de Melo Franco, Brasília, 1 de febrero de 1961, Archivo Histórico Itamaraty-Rio de Janeiro, Archivos Particulares de Afonso Arinos, estante 131, prateleira 1, pasta 16, maço A. 
zona de influencia. Esta premisa junto con otras, ${ }^{11}$ formó lo que se denominó la "Política Externa Independiente" (PEI).

Es interesante señalar que a pesar del entusiasta acercamiento con los africanos, al interior se continuaba negando el racismo. Por ello es notable el doble juego que se trazó, por un lado, se señaló la importancia que se tenía en apoyar a los negros que estaban lejos; fuera de Brasil, por otro, los descendientes de aquellos que se encontraban al interior del país, bajo la idea de democracia racial, supuestamente ya estaban amparados. Era la reinterpretación que fusionaba el pasado y el presente, donde el negro brasileño continuaba siendo, para el poder, objeto y no sujeto.

Por lo que la nueva política exterior brasileña hacia los jóvenes países africanos, tenía como punta de lanza su estrecha relación histórico-cultural. Incluso, Brasil se presentaba no sólo como modelo económico, sino como "un ejemplo de completa ausencia de prejuicio racial, junto con pruebas cabales de progreso sin solapar los principios de libertad" (Costa, 2007: I, 151).

En este mismo sentido, el presidente Quadros con el propósito de tender lazos con África y para demostrar la democracia racial vivida en Brasil, procuró nombrar un representante negro para la Embajada en Acra. El problema fue que el cuerpo diplomático no contaba con ninguno, por lo que Quadros tuvo que nombrar al periodista Raymundo Souza Dantas (1923-2002). ${ }^{12}$ La nueva y dinámica política exterior que deseaba implementarse, como

11 Jânio Quadros declaró frente al Congreso Nacional que su gobierno proponía adoptar, en resumen, quince puntos: 1) Respeto a los compromisos y a la posición tradicional de Brasil en el mundo; 2) Ampliación de los contactos con todos los países, incluso los del mundo socialista; 3) Contribución constante y objetiva a la reducción de las tensiones internacionales, sea en el plano regional o mundial; 4) Expansión del comercio externo brasileño; 5) Apoyo decidido al anticolonialismo; 6) Lucha contra el subdesarrollo económico; 7) Incremento de las relaciones con Europa; 8) Reconocimiento y atribución de la debida importancia a los intereses y aspiraciones comunes a Brasil y las naciones de África y de Asia; 9) Establecimiento y estrechamiento de relaciones con los Estados africanos; 10) Fidelidad al sistema interamericano; 11) Continuidad e intensificación de la Operación Panamericana; 12) Apoyo constante al programa de Asociación del Libre Comercio Latinoamericano; 13) La más estrecha y completa cooperación con las repúblicas hermanas de América Latina; 14) Relaciones de colaboración con EUA en defensa del progreso democrático y social de las Américas; 15) Apoyo a la onU para que constituyera la garantía efectiva e incontestable de la paz internacional y de la justicia económica.

12 Souza Dantas escribió África Difícil, Missão Condenada: Diário, publicado en 1965, donde narra su acercamiento con el pueblo de Ghana y su perspectiva del gobierno, en especial, la discriminación de la que fue objeto por parte de intelectuales y diplomáticos brasileños, al punto de escribir: "Felizmente, ni todo es motivo de amargura. Recibí carta de Brasil, dando noticia de los estudios de mi hijo Roberto. Fue un alivio en esta mañana 
se observa, tenía sus propios límites cuando, desde el ámbito institucional, se deseaba exhibir una democracia racial que era sólida sólo en el discurso.

Todas estas declaraciones tanto de Quadros como de Afonso Arinos acerca de la impecable relación entre negros y blancos y de la armoniosa sociedad multirracial que tanto ostentaban, debían tener algún anclaje en una sociedad en la que los líderes de los movimientos negros continuaban denunciando el racismo que se vivía en el país.

La solución a esto fue el soporte que una parte de la intelectualidad, tanto de centro como de izquierda, además de medios de información que, sensibilizados con la idea de apoyo a los países latinoamericanos y a los nacientes países afroasiáticos, adoptaron como suya las tesis de la nueva política exterior, dentro de la cual se insertaba la exaltación a la idea de la democracia racial.

El periódico O Jornal do Brasil, uno de los más prestigiados en Brasil, especialmente en Río de Janeiro, aceptó formar parte de este proyecto. Afonso Arinos, en su comunicación al Presidente Jânio Quadros el primero de abril de 1961, así lo expresó:

Tuve una larga conversación con el Doctor Nascimento Brito, director del Jornal do Brasil, y quedé muy satisfecho con ella. Efectivamente combinamos que el Jornal do Brasil, sin pérdida de su libertad de crítica, se integrará en la línea de la política exterior de Vuestra Excelencia, al punto de procurar ser una especie de intérprete autorizado de su pensamiento. Me parece inútil resaltar la importancia de ese apoyo de forma enteramente desinteresada, pues el Jornal do Brasil es probablemente hoy el diario más prestigiado de la prensa carioca. ${ }^{13}$

Otro periódico que también cubrió de forma continua la política exterior brasileña, y en particular la relación de Brasil con los países africanos, fue el periódico carioca Correio da Manhã, el que además de dar a conocer al público las acciones emprendidas por el gobierno brasileño, procuraba proporcionar información básica respecto de los países africanos, como

depresiva. Que Dios lo ayude, y, por otro, le quite de la cabeza la idea de ingresar en la carrera diplomática. Sé lo que sufrirá, por ser negro" (Dantas, 1965: 36-40).

${ }_{13}$ Viagem do ministro Afonso Arinos a Lisboa, Rio de Janeiro, $1^{\circ}$ de abril de 1961, Comunicación dirigida al presidente Jânio Quadros con carácter de secreto, Archivo Histórico de Itamaraty - Rio de Janeiro, Archivos Particulares Alfonso Arinos. Europa/África. 7 pastas. Série 34. 131-1-1. 
por ejemplo, el día de su independencia, productos exportados, extensión territorial y número de habitantes.

En Salvador, el periódico O Jornal da Bahia, incluso llegó a editar en inglés "The March of Africa Today", con lo que buscaba informar y acercar ambas poblaciones. El periódico A Tarde también emprendió semejante tarea al enviar un corresponsal que mandaba colaboraciones semanalmente para la columna "Caminhos da África" (Teles dos Santos, 2005: 45). Todas estas iniciativas tuvieron el objetivo de llenar el vacío de información que existía en torno del continente africano; desconocimiento que poseían amplios sectores de la población de todas las condiciones sociales.

El apoyo no sólo venía de los medios, sino también de políticos como Carlos Lacerda, que en su carácter de Gobernador del Estado de Guanabara apoyó iniciativas de acercamiento con los países africanos. Ejemplo de ello es la comunicación que envió al Ministerio de Relaciones Exteriores con el objetivo de buscar ayuda para transportar una delegación de africanos que participarían en la Conferencia sobre Enseñanza Libre. A lo que Arinos comunicó que el propio Presidente giraría instrucciones para utilizar un avión de la Fuerza Aérea Brasileña que, vía Dacar, recogería a los africanos para trasladarlos a Brasil. ${ }^{14}$ Del mismo modo, Lacerda envió otra comunicación epistolar al Ministro Arinos el 30 de mayo, haciéndole saber su intención de colaborar con el Itamaraty para recibir al presidente del Congo, Youlou Fulbert. ${ }^{15}$

Dado que las declaraciones gubernamentales recalcaban la idea de la armoniosa sociedad multirracial brasileña, el poder procuró también el

14 Carta del Ministro Afonso Arinos al Doctor Carlos Lacerda, 29 de marzo de 1961, Rio de Janeiro, Archivo Histórico Itamaraty-Rio de Janeiro, Archivos Particulares Afonso Arinos. Est. 131, prateleira 1, pasta 16, maço A. Las becas concedidas por el gobierno brasileño en la aún etapa de Quadros muestran el grado de importancia que adquirió África para Brasil. Ofreciendo catorce becas para estudiantes de Senegal, Ghana y Nigeria con duración de cuatro a seis años; seis becas de perfeccionamiento para estudiantes de posgrado concediendo dos para la RAU, dos para Marruecos y dos para Túnez con duración de uno a dos años. Además de sostener a lectores y conferencistas brasileños en Dacar e Ibada, Rabat y Acra, comenzando sus trabajos en 1962. Presidência da República, GP/ MRE/65, 17 abril 1961, con carácter de Urgente dirigido ao Ministério das Relações Exteriores, Archivo Histórico Itamaraty-Rio de Janeiro, Archivos Particulares Afonso Arinos. Jânio Quadros. 131-3-7.

15 Comunicação confidencial enviada pelo Ministro Afonso Arinos ao Excelentíssimo Senhor Carlos Lacerda, Governador do Estado da Guanabara, Brasília 6 de junio de 1961, Archivo Histórico Itamaraty-Rio de Janeiro, Archivos Particulares Afonso Arinos. Est. 131, prateleira 1 , pasta 16 , maço $\mathrm{A}$. 
apoyo de intelectuales, como José Honório Rodrigues, Eduardo Portella, Carlos Delgado, Ignácio M. Rangel y Gilberto Freyre, entre otros.

El principal teórico e historiador de las relaciones Brasil-África de aquella época fue José Honório Rodrigues. En su obra Brasil e África: Outro Horizonte, publicada en 1961, defendió que para Brasil, la "principal arma político-diplomática [era] la igualdad racial y social" (Rodrigues, 1961: 346), pues era gracias a ella que sería posible seducir a los africanos. Brasil además podría exhibir su fuerte mestizaje, anticolonialismo, antimperialismo, pacifismo y su defensa por el respeto hacia todas las naciones.

Para Honório, la formación igualitaria multirracial y multicultural le permitía a Brasil fortalecerse como un elemento constructivo dentro del inestable escenario internacional, afirmando que al contrario de Occidente o de la Unión Soviética, el país suramericano luchaba por derribar las diferencias y desigualdades conceptuales entre los hombres; procurando no destruir la tolerancia y las creencias espirituales (Rodrigues, 1961: 354).

Apoyado en Arnold Toynbee, quien en 1951 señaló que la superioridad y la virtud de Brasil radicaba en haber superado la idea de subordinar a las diferentes razas a prejuicios raciales, y siendo un extraño ejemplo dentro del mundo occidental, debía prestar un notable servicio a la humanidad con el propósito de reconciliar razas, religiones y culturas distintas. A ello, Honório agregaba que Brasil era un país victorioso por haber superado, dentro del propio territorio el prejuicio racial, con lo cual podía encarar el futuro con mayor confianza y mayor serenidad (Rodrigues, 1961: 355).

Como es posible advertir de las afirmaciones de Honório, Brasil estaba en una posición por demás privilegiada para convertirse no sólo en el ejemplo ideal de los nacientes países africanos, como ser el principal enlace de África con el resto del mundo. Dada la importancia de Honório como un teórico que creyó profundamente en estos postulados, su ámbito de acción traspasó los espacios académicos para convertirse en asesor del Itamaraty.

Los escritos y el trabajo de Gilberto Freyre también estuvieron presentes. Especial mención merece su colaboración con la revista semanal $O$ Cruzeiro, donde en varios momentos expresó la solidaridad de los brasileños con las poblaciones que formaban parte de los "territorios ultramarinos portugueses", así como la responsabilidad que debía tomar el país suramericano con el destino de otros pueblos, si bien, separados por la distancia física, pero cercanos en el ámbito cultural “y cuyo futuro, como 
cultura en desarrollo, tal vez [fuera] inseparable del futuro brasileño" (Freyre, 1961).

Freyre, siempre que le fue posible, hizo resaltar la especificidad de Brasil respecto a otros países de la región. Desde su libro Sobrados e Mucambos en donde declaró que Brasil, "nunca será, como Argentina, país casi europeo; ni como México o Paraguay, casi amerindio” (Freyre, 2006: 797). De lo que Freyre infería que, el país suramericano tendría una sustancia de la cultura africana que permanecería a lo largo de toda la formación y consolidación de la nación.

Esa premisa fue desarrollada en sus artículos y obras, reforzando la idea de Brasil como un tipo de civilización moderna que debía tomar el liderazgo de entre los países tropicales ${ }^{16}$ en el acercamiento con el continente africano. De tal manera que de una u otra forma, el autor pernambucano apoyó no sólo las nuevas directrices de la política exterior, sino que animaba a intensificarlas.

En ese sentido, Freyre se encontraba en concordancia con lo que el propio Quadros opinaba en el sentido de que Brasil estaba decidido a hacer valer su potencial en el escenario internacional, tanto en el plano económico como humano. Por lo que Brasil explotaría en su beneficio sus características como nación, entre ellas las culturales, para asumir su liderazgo en política internacional. Y si de potencial humano y de cultura se trataban, la mejor síntesis que podía utilizar, frente al mundo y en especial con África, era el mito de la democracia racial.

Fue la época en la que numerosas embajadas, consulados y misiones fueron instaladas. ${ }^{17}$ Periodo en el que se fundó el Centro de Estudios Afro Orientales de la Universidad Federal de Bahia (1959), que buscó

\footnotetext{
16 Gilberto Freyre, "O Brasil, líder da civilização tropical”, O Cruzeiro, Rio de Janeiro, sec.: Pessoas, coisas e animais, Rio de Janeiro, $1^{\circ}$ de julio de 1961, disponible en la Biblioteca Virtual Gilberto Freyre, http://bvgf.fgf.org.br/portugues/obra/artigos_imprensa/ brasil_lider.html

17 Brasília, 6 de abril de 1961, GP/MrE/53, Archivo Histórico Itamaraty-Rio de Janeiro, Archivos Particulares Afonso Arinos. Jânio Quadros. 131-3-7. Decreto 47.912, 11/03/1960 -Cria Legação em Gana; Decreto 50.383, 23/03/1961- Eleva à categoria de Embaixada a Representação em Acra; Decreto 50.503, 24/04/1961, Embaixada na República do Senegal; Decreto 50.605, 15/05/1961, Embaixada do Niger, Artigo $2^{\circ}$ A missão será cumulativa com a Embaixada do Brasil na República de Dahomey; Decreto 50.604, 17/05/1961 -Embaixada na República de Dahomey; Decreto 51.198, 16/08/1961, Embaixada na República da Nigéria. Leis do Brasil, 1960, v. 2; Leis do Brasil, 1961, v. 2, 4, 6. Arquivo Histórico Itamaraty- Rio de Janeiro.
} 
profundizar el conocimiento tocante a las culturas afroasiáticas y de la influencia de ellas en Brasil, así como el intercambio académico, pues hasta entonces de entre los intelectuales y académicos, sólo Gilberto Freyre había viajado a África.

Con la renuncia de Quadros en 1961, el planteamiento geopolítico que trazó sobrevivió, si bien, con ajustes y adaptaciones, la esencia y el dinamismo resistieron. Con el ascenso al poder de João Goulart, también conocido como Jango, se hizo hincapié en las relaciones culturales, la difusión de la cultura brasileña y el intercambio académico. Singular importancia cobraron los afrobrasileños - mestizos, criollos o africanos libertos- que, a principios del siglo XIX, comenzaron a regresar con sus familias al continente africano, siendo más evidente su presencia en Uidá, Adjaxé, Aneho, Badagry, Onim [Lagos] así como en otras ciudades que conformaban la Costa de Mina. Conocidos como agudás ${ }^{18}$ o brasileños en África, eran la viva imagen de los lazos afectivos que se tendían a través del Atlántico (Silveira, 2010: 333), ${ }^{19}$ representando un gran potencial en las aspiraciones de la política exterior brasileña en su acercamiento con los africanos.

Pero para vincularse con los africanos era necesario ir más allá de los discursos demostrando y exhibiendo los fuertes lazos que los unían. Así, la coyuntura de política exterior marcó una nueva etapa en la que los sujetos antes perseguidos por su color y cosmovisión pasaban por una fase en la que sus prácticas culturales eran usadas por la élite en el poder como un fuerte vínculo con los africanos. El problema fue que eran las prácticas culturales y no los sujetos quienes interesaban a la élite.

\section{LA ÉPOCA DE LOS GOBIERNOS MILITARES Y SU RELACIÓN CON ÁFRICA}

Con los militares en el poder a partir de 1964, África pasó a ser vista en términos ideológicos. Fue la búsqueda por "proteger al continente africano"

\footnotetext{
18 Denominación yoruba que significaba extranjero, brasileño o católico

${ }_{19}$ Paulina Alberto en su artículo "Intecâmbios africano-baianos na reinvenção da democracia racial", 1961-1963, muestra el interesante caso de la brasileña Romana da Conceição, quien en 1899 embarcó con su madre y hermanos hacia Lagos a pedido de su abuela, una africana que fue llevada a Brasil como esclava. El caso se volvió importante, no porque fuera la primera brasileña radicada en África que volviera a Brasil, sino debido a que el Itamaraty fue quien emitió una invitación oficial, recibiéndola, entre el 17 de mayo y el 8 de agosto de 1963, con todos los honores dedicados a un visitante distinguido.
} 
de los avances comunistas, formando parte de la estrategia de seguridad brasileña en el hemisferio del Atlántico sur. Por ello, no extraña que privilegiara su relación con Portugal, reforzando la alianza Brasilia-Lisboa-Pretoria. El giro en las relaciones con África fue de fondo. África fue incluida en el plan de seguridad nacional brasileña como parte de su frontera oriental, reforzando la idea de un Brasil "protector" de África contra el comunismo.

A partir de esta época, comenzó a mostrarse una democracia racial diferente. En vez de continuar exaltando el mestizaje, fundamento de la propuesta de Freyre, se destacó la herencia negra, haciendo más eficaz el acercamiento con los líderes africanos. De tal manera que Salvador, ciudad que concentraba una importante población negra, cobró una gran proyección internacional. Las prácticas culturales pasaron a ser usadas con mayor vehemencia en el discurso y a ser adecuadas por el Estado como un asunto de su competencia.

Pero los movimientos negros e intelectuales críticos que discordaban tanto de la democracia racial como de la apropiación del Estado de sus elementos culturales, no podían manifestar abiertamente su rechazo. La dictadura militar no sólo reprimió las actividades políticas, sino que con la Ley de Seguridad Nacional, la democracia racial pasó a ser un dogma intocable (Nascimento, 1982: 31).

A partir de 1967, la lectura que el poder, no sólo político como económico, tenía sobre Bahia y las tradiciones de influencia africana cobraron mayor fuerza. Fue la época en la que se utilizaron los nombres de los orixás para nombrar hoteles, edificios y tiendas, así como el uso de elementos religiosos para hacer obras cinematográficas y musicales (Teles dos Santos, 2005: 66). Es de esta manera que la industria cultural entró en escena, despedazando el verdadero sentido de la religiosidad, para sólo reconocer partes y no el conjunto (Adorno, 2011: 15). No se reconocía el verdadero sustrato políticorreligioso que esas prácticas tenían como símbolo de organización y solidaridad históricas, sino que sólo se exaltó la parte folclórica que representaba atracción turística y servía de vehículo a los intereses de la política exterior. Para el poder económico se convirtió en elemento de consumo especialmente dirigido a los turistas.

Brasil conseguía posicionarse de manera sólida como el más importante interlocutor de África. Pero uno de sus pilares de política internacional, la democracia racial, no sólo era cuestionada en el interior, sino que comenzaba a perder su carácter de excepcionalidad en el ámbito internacional. 
Fue fuera de Brasil que la realidad comenzó a mostrar cambios, especialmente en Estados Unidos de América, país con el que siempre resaltó las fuertes diferencias que existían en el trato con el negro. Aquel país enfrentaba el movimiento por los derechos civiles que buscaba modificar la desigual relación que existía entre blancos y negros. ${ }^{20}$

Las presiones también venían de la fuerte embestida de la comunidad internacional contra el régimen del apartheid. Si bien, Brasil fue el primero en firmar la Convención Internacional sobre la Eliminación de Todas las Formas de Discriminación Racial, en 1966 el Ministro de Relaciones Exteriores, Juracy Magalhães, en la XXI sesión ordinaria de la Asamblea General de la ONU, resaltaba que Brasil [cito al Ministro] era el:

ejemplo prominente [...] de una verdadera democracia racial, donde muchas razas viven y trabajan juntas, $[\ldots]$ sin miedo o favores, sin odio o discriminación. [...] Aunque la nueva Convención sea, por lo tanto, superflua en lo que concierne a Brasil, nosotros la recibimos con alegría para servir de ejemplo a ser seguido por otros países que se encuentran en circunstancias menos favorables. [...] Que el ejemplo de Brasil, y la moderación sin esfuerzos, tolerancia serena y respeto mutuo en nuestras relaciones raciales sean seguidas por todas las naciones multirraciales (Seixas, 2007: 221).

El discurso del Ministro Magalhães hacía hincapié en la democracia racial como un fuerte eslabón de la política exterior brasileña. Por lo tanto, para el poder público, el país estaba exento de cualquier prejuicio y aquel instrumento internacional era inaplicable para ellos. Además, resaltaba el orgullo de vivir en un lugar sin problemas raciales y colocaba a Brasil como ejemplo de convivencia armoniosa.

Pero al mismo tiempo, los líderes afrobrasileños denunciaban las reiteradas formas de discriminación, ya en el campo laboral, ${ }^{21}$ escolar, e incluso recreativo. Pero la represión alcanzó también al movimiento negro y líderes

20 Para conocer con mayor profundidad el movimiento por los derechos civiles en Estados Unidos de América consultar: De la Serna, Juan Manuel. (1999); Los afronorteamericanos (Historia y destino). México: Instituto de Investigaciones Dr. José María Luis Mora; Luther King, Martin. (2010); Un sueño de igualdad. Madrid: Público-Biblioteca Pensamiento Crítico.

21 En noviembre de 1968, técnicos del Ministerio de Trabajo y del Tribunal Superior del Trabajo propusieron que ante la discriminación en el sector laboral, se implementara una ley para que las empresas privadas estuvieran obligadas a contratar un porcentaje de empleados de color. El gobierno, si bien aceptó casos de discriminación, la solución, creía, sería más en el ámbito judicial que laboral (Teles, 2005: 104-105). Es interesante observar que si en Estados Unidos de América ya se estaban discutiendo las acciones 
como Abdias Nascimento enfrentaron el exilio. La situación empeoró en 1968 con el Acto Institucional 5 (AI-5). ${ }^{22}$

Así, se entiende que desde finales del gobierno Médici y durante el mandato de Ernesto Geisel (1974-1979), se intensificara la apropiación de los elementos culturales afrobrasileños y al mismo tiempo se incrementa la relación con África, especialmente en el ámbito comercial.

La intervención del poder público estaba cada vez más presente dentro de las representaciones culturales afrobrasileñas. Éstas eran exhibidas como parte del folclor del país y como atracciones turísticas. En el caso concreto de la capoeira, fue en 1973 cuando pasó a ser deporte nacional y, en consecuencia, caracterizada como símbolo nacional, identificándola como parte del mestizaje y propio de la democracia racial. Así, la industria cultural aprovechó la coyuntura para apropiarse de las expresiones culturales y dentro de la lógica capitalista fueron convertidas en mercancías, que resultaron ampliamente rentables para la burguesía local. En esa lógica perversa se reforzaba el mito de la democracia racial. Una que al exhibir los elementos negros de la sociedad, se ufanaba de su igualdad, y por otro lado, continuaba practicando, bajo sus innumerables mecanismos sutiles, el prejuicio y la exclusión.

Mientras tanto, en el ámbito internacional, el Itamaraty seguía aludiendo una incuestionable democracia racial brasileña. En sus cinco primeras relatorías enviadas al Comité para la Eliminación de la Discriminación Racial, presentadas entre 1970 y 1978, refrendaba las relaciones armoniosas en Brasil sin tener necesidad de adoptar ninguna medida legislativa, judicial o administrativa, dado que la Constitución brasileña, incluso, cito, era "más rigurosa y eficaz en la defensa de las buenas relaciones interraciales que el propio instrumento internacional" (Albuquerque e Silva, 2008: 70-71).

Durante el gobierno de Ernesto Geisel, el ministro de relaciones exteriores, Antonio Azeredo da Silveira, adoptó la postura de que África era

afirmativas con sus consecuentes cuotas en educación y empleo para minorías étnicas, en Brasil aún no se recibía con agrado tales medidas.

22 El AI-5, otorgaba al Presidente de la República, entre otras atribuciones, la facultad de suspender los derechos políticos de cualquier ciudadano por un plazo de diez años. Dentro de la suspensión de esos derechos se encontraba la suspensión del derecho de voto, prohibición de actividades o manifestaciones referentes a los asuntos de naturaleza política, incluso libertad vigilada y prohibición de frecuentar determinados lugares. El Presidente además podía decretar el estado de sitio. El AI-5 suspendió la garantía de habeas corpus en los casos de crímenes políticos, contra la seguridad nacional, el orden económico y social y la economía popular. 
un vecino de Brasil, teniendo en el Atlántico, más que una vía de comunicación, un lazo de unión. Con ese planteamiento presente, la indicación a todos los ministros fue que la nueva posición de Brasil sería el alejamiento de la solidaridad colonialista en relación con Portugal.

Si en el discurso esto ya había sido manifestado por otras administraciones, en ésta la diferencia radicó en el reconocimiento, incluso antes que Portugal, de la independencia de Guinea Bissau y, posteriormente de los gobiernos de Angola y Mozambique (Spektor, 2010: 94-95). Con lo cual, Brasil logró no sólo estrechar aún más los lazos de fraternidad con África, sino quizás más importante, insuflarle veracidad y confianza plena a sus discursos y acciones con el continente.

Estas acciones se reflejaron no sólo en una gran cantidad de visitas oficiales enviadas a diversos países africanos por Brasil, así como la instalación de nuevas embajadas brasileñas tanto en los países recién independientes de lengua portuguesa como en Benín y Guinea Conakry. Pero quizás lo más interesante de todo fue un hecho que, sin duda, demuestra la eficacia del gobierno brasileño para "vender" su idea de democracia racial a la brasileña.

En 1977, fue organizado el "II Festival Mundial de Artes y Culturas Afro-Negras", en Lagos. Brasil fue representado por una nutrida delegación. Durante la celebración, el país suramericano fue atacado por representantes de Estados Unidos de América en materia de política africana y por el problema de democracia racial existente en Brasil. Como recuerda el exministro Azeredo: "ellos afirmaron, en plena conferencia, que decir que no había prejuicio racial en Brasil era un hecho infundado. La cosa más curiosa es que todos los africanos se levantaron en nuestra defensa. Eso fue muy significativo" (Spektor, 2010: 100).

Esta situación es muy interesante en varios aspectos. Primero, EUA con la lucha de los derechos civiles por parte de la población afronorteamericana, a esas alturas, ya había experimentado cambios importantes dentro de su legislación, por lo que no podía ser más visto, como antes, una antítesis de lo que ocurría en el país suramericano.

Segundo, la posición de Brasil respecto a la democracia racial estaba puesta en entredicho a escala internacional por líderes negros e intelectuales que, con el golpe militar tuvieron que salir exiliados, entre ellos Abdias Nascimento, quien radicó e impartió clases, en EU. Abdias aprovechó todo tipo de foro organizado por afronorteamericanos, y por supuesto, actos llevados a cabo en la propia África, con el fin de divulgar la situación compleja 
en la que realmente vivían los negros brasileños (Nascimento, 1982: 13). Es en ese ambiente que pueden ser comprendidas las declaraciones de la delegación estadounidense.

Pero tampoco puede sorprender la reacción y defensa de los africanos frente a aquellas aseveraciones. Es innegable la eficacia de la extraordinaria y amplia propaganda que el gobierno brasileño se encargó de divulgar en África y eso es un hecho que no puede soslayarse. Como tampoco puede olvidarse que Brasil representó un papel importante para ayudar a destrabar la situación de las colonias portuguesas africanas, que desembocó en las independencias. Brasil asumía constantemente una posición favorable a las preocupaciones y aspiraciones del continente.

Muestra de ello es que Nigeria, como señaló el propio Azeredo, comenzó un acercamiento más decidido con Brasil a raíz de que éste manifestara comprensión respecto a los problemas africanos y su posición abiertamente anticolonialista practicada en la época del gobierno de Geisel (Spektor, 2010: 105).

Las muestras de cordialidad, respaldo y solidaridad se daban desde compartir experiencias en los ámbitos de la salud y educación, hasta los tecnológicos. Al mismo tiempo, los países africanos estaban luchando por consolidar su independencia. Brasil no representaba sometimiento, por el contrario, beneficios.

A lo anterior, hay que agregar que el ministro Azeredo, en innumerables ocasiones y bajo diferentes pretextos, declaró que Brasil no sólo era un país mestizo, sino además en contra del racismo. Así lo declaró en ese mismo año de 1977, en una entrevista hecha por la periodista mexicana Verónica Rascón:

[Brasil] jamás se aliaría a países, por ejemplo, que discriminaran racialmente. Eso sería contra el alma nacional brasileña. Brasil es un país mestizo. Y se enorgullece de serlo. Brasil sólo es grande cuando reconoce plenamente que es un país mestizo. Y se trata de un mestizaje amplio. Nosotros tenemos africanos, indios, todas las clases de mezcla. Tenemos asiáticos, es la mayor población japonesa fuera de Japón. Entonces, este país es así, no puede ser otra cosa que un país que reconoce todas las aspiraciones de razas que fueron expoliadas y que están en proceso de liberación. Así es Brasil. Es una tontería hablar de otras cosas. ${ }^{23}$

23 Entrevista do Chanceler Azeredo da Silveira, concedida à jornalista Verónica Rascón, da TV Canal 11 do México, no Palácio Itamaraty de Brasília, em 21 de dezembro de 1977, 
Como se puede percibir, el discurso político no dejaba dudas sobre lo que proyectaba y "vendía" como parte de sus principios de política exterior. Las diversas entrevistas concedidas, además de las acciones emprendidas por Brasil en los países africanos, no dejaban libertad de acción para que los líderes africanos censuraran las declaraciones del ministro Azeredo, por el contrario, existía cierta presión ejercida por el Itamaraty para apoyar el discurso de mestizaje y cordialidad entre las razas. De ahí que no resulte nada "curiosa", como señaló el ministro Azeredo, la defensa de los africanos, sino sintomático con lo que acontecía en las relaciones entre Brasil y África.

Dada la debilidad que comenzaba a mostrar el discurso del poder en torno de la democracia racial, era necesario tomar ciertas medidas. En 1976 surgió la propuesta para establecer el Parque Histórico Nacional de Zumbi, en el municipio Unión de los Palmares en Alagoas. En octubre del mismo año se reunieron varios organismos tanto federales y estatales como municipales de cultura y turismo, con el propósito de evaluar las posibilidades de fundar el parque. La idea de fondo era "imbricar valores, tradiciones y personajes afrobrasileños en el ámbito del binomio cultura/turismo" (Teles dos Santos, 2005: 95).

La propuesta y posterior aceptación parecería un contrasentido en un periodo de régimen militar, pues Zumbi-Palmares han sido considerados, para los afrobrasileños, símbolos de lucha por la libertad y contra toda forma de represión. Sin embargo, no se pueden minimizar las críticas que, a nivel internacional, se le hacían a Brasil sobre las prácticas de racismo y exclusión en contra de la población afrodescendiente. La idea entonces, era no sólo mostrar tanto dentro como fuera del país que la armonía estaba presente, sino que además, el poder político y, además militar, reconocía los símbolos de los negros y mestizos brasileños como propios.

Interesante, además, que los órganos institucionales no sólo estaban conformados por aquellos con objetivos culturales, sino también turísticos. Una vez más, era la idea de focalizar el desarrollo de actividades turísticas que, se sabía, podía ser atractivo para un determinado grupo de viajeros que estaba despuntando en aquellos años, los afronorteamericanos. ${ }^{24}$ Es en esa

Archivo CPDoc-Fundación Getúlio Vargas, Archivo Antônio Azeredo da Silveira, Ass mre ag 1977.11.25.

24 Jocélio Teles recuerda que el 23 de marzo de 1973 fue publicada la noticia en la que se daba a conocer que estarían llegando a Bahia cinco mil negros estadounidenses, todos da Georgia, para conocer las tradiciones culturales afrobrasileñas. La visita se encontraba dentro de un programa hecho por una agencia de turismo estadounidense, especializada 
población extranjera, singularmente interesada en las raíces afrobrasileñas, que en Bahia, vía Bahiatursa creada en 1972, emprendió una importante campaña con el fin de atraerlos.

Lo importante en todo caso, es observar que el cuestionamiento de la democracia racial ya era planteado no sólo por los propios brasileños, como por aquellos que antes habían sido señalados como uno de los ejemplos de intolerancia y discriminación racial, como lo era Estados Unidos de América.

Aunque el propósito del poder politicoeconómico fue el de utilizar las prácticas afrobrasileñas como un atractivo turístico, eso no redundó en que, por ejemplo, los propios creadores, fueran protegidos. Los casos de los maestros de capoeira, Bimba ${ }^{25}$ y Pastinha son una muestra de ello. Ambos murieron desamparados, padeciendo dificultades financieras y sin ningún apoyo institucional que les permitiera vivir sus últimos días de forma digna. Incluso, como en el caso de Pastinha desalojado de su escuela con el objetivo de convertir aquel espacio en un restaurante (Cypriano, 2009: 42).

De tal manera que por un lado, los artistas, creadores y difusores de las prácticas afrobrasileñas eran utilizados por los órganos públicos y privados, tanto para fines de política internacional como interna. Política exterior y turismo fueron el centro de las preocupaciones del poder político-económico, en tanto que los afrobrasileños continuaban abandonados y desprotegidos.

\section{LA DEFENSA DE LOS AFROBRASILEÑOS DE SUS PRÁCTICAS CULTURALES}

A pesar de la actuación y de los discursos emanados por parte del gobierno brasileño, así como de las instituciones culturales-turísticas, la folclorización de los elementos culturales de los descendientes africanos en Brasil fue llevada adelante hasta cierto punto. Los sujetos directamente afectados por esas acciones no se quedaron inmóviles. La reacción de los afrobrasileños fue aprovechar la coyuntura que dicha exposición pública dio a sus prácticas, así como la defensa de las mismas. Por ejemplo, en lo que se refiere al Candomblé, existieron manifestaciones públicas denunciando la

en la atención de la población negra; además, la agencia tendría como propósito enviar a Brasil alrededor de un millón de negros con un alto poder adquisitivo, a fin de que pudieran descubrir su pasado africano en tierras brasileñas (Teles dos Santos, 2005: 115).

25 Ver documental de Luiz Felipe Goulart, Mestre Bimba. O Rei da Capoeira, Salvador, Fundação Mestre Bimba, 2007. 
folclorización del mismo. Intelectuales como Edison Carneiro señalaron en el "Primer Festival Bahiano de Folclore", "que el candomblé era una institución, un culto permanente y específico a un determinado grupo, no siendo folclor institucionalizado" (Teles dos Santos, 2005: 131). Es decir, Carneiro rechazaba que desde las esferas del poder las prácticas culturales no fueran respetadas como parte de la identidad ${ }^{26}$ del negro, y que por el contrario, fueran sometidas a la lógica mercantil, inferiorizando su valor cultural.

Pero el rechazo de esta situación también provino de intelectuales negros como Abdias de Nascimento; este líder, mediante y desde la creación del Teatro Experimental Negro ${ }^{27}$ y del periódico Quilombo, ${ }^{28}$ así como desde sus diversas actividades y artículos, denunció, entre otros, los agravios que la población negra enfrentaba. A finales de la década de los sesenta, puntualmente señaló el evidente retroceso de la participación del negro en el campo de la vida política brasileña. El negro contaba con escasos lugares en el poder legislativo y los pocos que lo alcanzaban eran discriminados abiertamente (Nascimento, 1982: 69).

Todavía más, para finales de los años sesenta, Abdias no sólo refutó la idea de la democracia racial, la que calificó como un eslogan que servía para disfrazar la discriminación y el lento desaparecimiento del negro (Nascimento, 1982: 78), ${ }^{29}$ sino además llamó la atención en torno de la

26 Identidad entendida como "la representación que tienen los agentes (individuos o grupos) de su posición (distintiva) en el espacio social, y de su relación con otros agentes (individuos o grupos) que ocupan la misma posición o posiciones diferenciadas en el mismo espacio" (Giménez, 2009: 47).

27 El Teatro Experimental Negro (TEN), fue fundado en 1944, en Río de Janeiro, por Aguinaldo Camargo, José Herbel, Teodorico dos Santos, Abdias de Nascimento y Alberto Guerreiro Ramos. Su objetivo inicial consistió en permitir que el negro fuera incorporado a los escenarios, convirtiéndolo en sujeto protagónico y activo dentro de las piezas teatrales. Sin embargo, los alcances del TEN sobrepasaron sus actividades culturales y logró convertirse en un espacio de resistencia en contra del prejuicio y la discriminación, por medio del fortalecimiento de la cultura africana y la elevación de la autoestima de los negros brasileños.

${ }^{28}$ Quilombo fue una publicación auspiciada por el Teatro Experimental Negro y su director, Abdias de Nascimento. A lo largo de sus diez números (diciembre de 1948 a julio de 1950) se convirtió en un espacio cultural que tuvo la virtud de ser el semillero de nuevas ideas políticas generadas por los propios negros brasileños. En Quilombo es posible encontrar artículos diversos referentes al negro, desde denuncias de discriminación hasta cuestiones de literatura, historia o religión.

29 Abdias do Nascimento hacía notar en aquel momento que los negros eran quienes más padecían la inseguridad y violencia, y que debido a la indiferencia del poder público, la 
supuesta convivencia cordial entre las razas, de la cual se enorgullecía Portugal, señalando que "el prejuicio de color brasileño [era] secular y autóctono. De pura cepa lusitana" (Nascimiento, 1982: 70).

Pero la movilización no sólo se gestó desde los intelectuales y los líderes negros. Es importante resaltar que durante la época militar, organizaciones de diversa índole y en diferentes partes de Brasil comenzaron a hacerse presentes. Desde los masivos bailes con música soul en Río de Janeiro, Bahia y en São Paulo; el grupo de carnaval Ilê Aiyê, los grupos teatrales como el Evolução, en Campinas o la Sociedad de Estudios de la Cultura Negra en Brasil con sede en Salvador (1974), hasta organizaciones como el Grupo Palmares en Porto Alegre (1971); el Centro de Cultura y Arte Negra (Cecan), fundado en 1971, en São Paulo, el cual fue organizado por un grupo de artistas e intelectuales negros. Sin olvidar lo logrado en la Universidad Cândido Mendes, en el Centro de Estudios Afro-Asiáticos (CEAA) donde se organizaron los "Diálogos aos Sábados", que reunían estudiantes con el propósito de discutir la cuestión racial en Brasil. Producto de esos debates surgió el Instituto de Investigación de las Culturas Negras (IPCN) y la Sociedad de Intercambio Brasil-África (Sinba) (Hanchard, 2001:109-110). Algunas de estas organizaciones lograron formar periódicos que les permitieron divulgar sus ideas y abrir el debate sobre la cuestión racial en Brasil. ${ }^{30}$

población negra era la que más sufría por el elevado número de decesos causados por la violencia. Durante aquellos años, la información oficial respecto al número de homicidios de la población negra era difícil de saber, fue sólo hasta 1996 cuando se comenzó a reunir información acerca de la raza/color de las víctimas y fue en el año 2002 cuando finalmente pudieron ser analizadas las cifras. El último informe del Mapa de violencia en Brasil revela que desde 2002 ha existido una tendencia en la caída del número absoluto de los homicidios en la población blanca y en el aumento en los números de la población negra. Tendencia que se observa tanto en el conjunto de la población, como en la población joven. En el año 2002 los homicidios de negros fueron 26,952, mientras que las víctimas blancas sumaron 18,867. En tanto, en 2010, murieron 34,983 negros, mientras que se registraron 14,047 decesos de personas blancas. Es decir, durante ese periodo, 272,422 negros fueron muertos, con una media de 30,269 asesinatos al año. Mientras que en el mismo lapso, murieron 144,174 blancos. Del total de negros muertos durante el periodo 2002-2010, 159,543 eran jóvenes (Waiselfisz, 2012).

30 Para conocer con mayor detalle cada una de las organizaciones, consultar: Alberti, Verena y Araujo Pereira, Amilcar. (2007); Histórias do movimento negro no Brasil. Depoimentos ao CPDOC. Rio de Janeiro: Pallas-CPDOC-FGV; Araujo Pereira, Amilcar. (2013); O mundo negro. Relações raciais e a constituição do Movimento Negro Contemporâneo no Brasil. Rio de Janeiro: Pallas-Faperj; Ferreira da Silva, Joana Maria. (2012); Centro de Cultura e Arte Negra-Cecan. São Paulo: Selo Negro; Hanchard, Michael George 
Cabe resaltar que otras formas de resistencia comenzaron a hacerse presentes; por ejemplo, el Candomblé se valió de dicha exposición pública que el poder les brindó, para evitar que los prejuicios en contra de su religión continuaran propagándose, exigiendo respeto a sus creencias y cosmovisión del mundo.

De esta forma, numerosas organizaciones fueron creadas a finales de la década de los setenta y principios de los años ochenta. Rufino dos Santos calculó que durante aquel periodo trabajaban alrededor de "cuatrocientas organizaciones, contando con aproximadamente tres mil activistas, capaces de, eventualmente, movilizar, en los momentos de tensión, confrontación o celebración, 25 mil simpatizantes más de clase media baja o que se encontraban en el proceso de llegar a aquel status (Santos, 1994: I,94).

Organizaciones que permitieron la conformación de un grupo más amplio y que hasta el día de hoy ha sobrevivido como el Movimiento Negro Unificado. Conocido en un primer momento como Movimiento Unificado Contra la Discriminación Racial (MUCDR) surgió en junio de 1978, cuando varias organizaciones del movimiento negro se unieron para protestar por tres sucesos de discriminación y prejuicio racial. La muerte del trabajador negro y padre de familia Robson Silveira da Luz, ocurrida el 28 de abril en la 44o. Distrito Policial de Guaianazes, en São Paulo. Acusado de robar fruta en un mercado al aire libre, fue preso y torturado, falleciendo a causa de la tortura. Por la expulsión de cuatro niños negros del equipo juvenil de voleibol del Club de Regatas Tietê sin más justificación; así como por el asesinato de Nilton Lourenço a manos de un policía en el barrio de Lapa (Alberti, 2007: 150).

(2001); Orfeu e o poder. Movimento Negro no Rio e São Paulo (1945-1988). Río de Janeiro: Universidade do Estado do Rio de Janeiro; Jesus Félix, João Batista de. (2000); Chic Show e Zimbabwe e a construção da identidade nos bailes Black Paulistanos. São Paulo: Universidad de São Paulo, fflch; Jesus Felix, João Batista de. (2005); Hip Hop: Cultura e política no contexto paulistano. São Paulo: UsP-FFLCH-Programa de Posgrado en Antropología Social; Maia da Silva, Rita de Cassia. (2003); O negro-espetáculo. O bloco afro Ilê Aiyê na ressignificação e recepção da imagem do negro em Salvador. Salvador: Tese de Doutorado, ufBa-Programa de Pós-graduação em Comunicação e Cultura Contemporâneas, 2 vol.; Reid Andrews, George. (1988); Negros e brancos em São Paulo (1888-1988). São Paulo: Edusc; Silva Souza, Florentina da. (2005); Afro-descendência em Cadernos Negros e Jornal do MNU. Rio de Janeiro: UERJ-Autêntica; Sousa Junior, Walter Altino de. (2007); O Ilê Aiyê e a relação com o Estado: interfaces e ambiguidades entre poder e cultura na Bahia. Salvador: Fundação de Amparo à pesquisa do Estado da Bahia, Visual Editora y Gráfica Rápida LTDA. 
Si bien estos acontecimientos eran frecuentes, la coyuntura histórica hizo la diferencia, pues la comunidad negra organizada no sólo había crecido sino que además se había fortalecido. Ello permitió que varias organizaciones, entre ellas, el Centro de Cultura y Arte Negra, Brasil Jovem, Instituto Brasileño de Estudios Africanistas (Ibea) fundado por Clóvis Moura, la Cámara de Comercio Afro-Brasileña, el Núcleo Socialista Afro-Latinoamérica, entre otros, se reunieran en una imponente manifestación el 7 de julio de 1978 en las escaleras del Teatro Municipal de São Paulo, aunque fue desde el 18 junio que comenzaron los preparativos.

Dada la dura represión y con el propósito de disuadir a la policía, los organizadores no sólo entregaron una carta al secretario de Seguridad del estado de São Paulo solicitando la liberación de la plaza con la finalidad de eliminar el riesgo de enfrentar el aparato de represión policiaca, sino que además convocaron a diversos sectores nacionales y especialmente a la prensa internacional. Como señaló Milton Barbosa: "cuando nosotros ocupamos la plaza, no tenían cómo reprimirnos porque Brasil vendía una imagen de país no racista. Compraba petróleo a Nigeria, en Angola y fue el primero en reconocer la liberación de los países africanos, en especial Angola" (Alberti, 2007: 152).

Como es posible advertir, los afrobrasileños aprovecharon las mismas contradicciones que el propio sistema había generado para evitar el tema del racismo en Brasil. Pero además, se sirvieron de los sectores contrarios al régimen militar, en especial los medios de comunicación internacionales, para abrirse propaganda, difusión y, lo más interesante, evitar la represión en el centro de una de las ciudades más importantes de Brasil, con lo cual daba un ejemplo de cómo era posible beneficiarse de las múltiples contradicciones internas generadas por el poder.

De tal forma que el mitin resultó un éxito, pues además de reapropiarse de un espacio público, el acto recibió innumerables muestras de apoyo de diversas personalidades negras, como Abdias de Nascimento y Lélia González, así como de otros estados del país, entre ellos, Minas Gerais, Pernambuco, Bahia, Sergipe, Alagoas, Rio de Janeiro y del propio São Paulo así como de la Casa de detención de São Paulo. ${ }^{31}$

31 El Núcleo Negro Socialista trabajó dentro de la Casa de Detención de São Paulo proveyendo abogados y copias de los procesos con la finalidad de ayudar a los reclusos. Sin embargo, también les proporcionaba libros, con lo cual los presos lograron articular debates referentes al negro (Alberti, 2007: 151). 
La movilización en gran parte estuvo organizada por los jóvenes conocidos como Núcleo Negro Socialista, quienes venían trabajando desde tiempo atrás en la agrupación clandestina, Convergencia Socialista, ${ }^{32}$ organización fundada el 28 de enero de 1978, en São Paulo, teniendo por base el marxismo trotskista. El Núcleo Negro Socialista junto con otras organizaciones negras, se reunieron al día siguiente del mitin para planear la convocatoria de un congreso nacional para el día 23 de julio del mismo año. La primera propuesta fue modificar el nombre, a fin de responder a los propósitos y objetivos de la organización. De tal modo que pasó a conocerse como Movimiento Negro Unificado (Alberti, 2007: 156). La segunda propuesta fue elaborar una carta de principios, así como los estatutos.

Sin embargo, la disputa entre los diferentes grupos que componían la naciente organización se reflejó especialmente en la formulación del estatuto; mientras que unos defendían que la organización sería movilizadora con el fin de trabajar con la población negra, otro sector defendía la idea que la organización tuviera una base reivindicativa, siendo este el grupo que se impuso. Es por ello que en la Asamblea Nacional del 9 y 10 de septiembre en Río de Janeiro, se aprobaron los estatutos que comienzan afirmando que el MNU "es un movimiento reivindicativo, constituido por personas sin distinción de sexo, o instrucción y que asuman voluntariamente su programa de lucha” (2007:161).

En la misma asamblea de septiembre también fue aprobada la "Carta de Principios". Su importancia radica en varios aspectos. Fue la primera vez que los propios afrobrasileños redactaron una definición del "ser negro", siendo "todo aquel que posea en el color de la piel y en el rostro o en el pelo, señales características de esa raza" (Movimiento Negro Unificado, 1988: 18). De esta forma, existió un pleno reconocimiento de sí mismo, al tiempo que amplió la noción del negro, que hasta antes de ésta sólo se limitaba al color de la piel, logrando hacer partícipes del movimiento a los mulatos, quienes habían sido excluidos de muchas organizaciones negras por considerar que, al ser calificados por algunos como blancos, no comprendían los objetivos de los negros.

Segundo, la "Carta de Principios" señaló como su principal objetivo:

32 Convergencia Socialista tiene sus antecedentes en la Liga Obrera, de inspiración trotskista, la cual fue fundada a finales de 1973 por brasileños exiliados en Argentina que previamente habían sido parte de Acción Popular, el Partido Comunista Brasileño Revolucionario y el Movimiento Nacionalista Revolucionario (Ibid.). 
La defensa del pueblo negro en todos los aspectos políticos, económicos, sociales y culturales a través de la conquista de mayores oportunidades de empleo, mejor asistencia a la salud, a la educación y a la habitación; revaloración de la cultura negra y combate sistemático a su comercialización, folclorización y distorsión; extinción de todas las formas de explotación, represión y violencia; y libertad de organización y de expresión del pueblo negro (1988: 18).

Si bien, la mayor parte de estos propósitos ya habían sido estipulados en otras organizaciones, e incluso bajo diversos mecanismos ya habían manifestado su rechazo acerca de la folclorización y mercantilización de sus elementos culturales, lo relevante es que esta "Carta de Principios" se inscribió en una coyuntura histórica particular. En primer lugar, Brasil vivía la época conocida como de apertura política ${ }^{33}$ con lo cual, a pesar de la represión y espionaje que aún se vivía, lograron manifestar sus inquietudes. Segundo, era la primera vez que se unían diversos grupos que luchaban desde diferentes ángulos en contra de la discriminación para, desde una sola voz, interpelar al poder sobre el racismo institucional-estructural que padecían los negros en Brasil. Finalmente, sus reivindicaciones se hacían desde una organización con fuertes cimientos políticos y no sólo culturales-académicos, como ocurrió durante las décadas anteriores.

Importante señalar que el MNU no se aisló del resto de las luchas de la sociedad. Esto fue importante teniendo en consideración que en las anteriores organizaciones negras, sus demandas no buscaron vehicularse con otros grupos, con lo que su accionar se presentaba de forma aislada. Este avance devino, en gran parte, de que un sector de los fundadores estaba ligado al movimiento estudiantil y al obrero, saltando de esa plataforma a una militancia negra. Por ello no sorprende que de forma contundente la "Carta de Principios" señale que se solidarizan "con toda y cualquier lucha reivindicativa de los sectores populares de la sociedad brasileña que busque la conquista de sus derechos políticos, sociales y económicos y con la lucha internacional contra el racismo" (Movimiento Negro Unificado, 1988: 18).

33 La llamada Apertura, fue un proyecto de distención política que se configuró en una lenta y gradual transición para la democracia. Inició durante el gobierno de Ernesto Geisel (1974-1979), con la participación de su auxiliar directo, el general Golbery do Couto e Silva, quien fungía como Jefe del Gabinete Civil de la Presidencia de la República. El proceso terminó en marzo de 1985, cuando asumió el cargo de presidente José Sarney, sustituyendo al último presidente del régimen militar, el general João Figuereido (Alberti, 2007: 122). 
Este acercamiento con el resto de los grupos políticos-sociales, por un lado, devino en la década de los ochenta en una aproximación con los partidos políticos que observaron en el Movimiento Negro un grupo de presión importante y del cual buscaron obtener sus votos. Por otro, fue un claro apoyo en la lucha de los trabajadores que desde mayo de 1978 comenzaron a movilizarse por el incremento salarial, encabezados por Luiz Inácio Lula da Silva, los metalúrgicos del ABC paulista organizaron una gran huelga que movilizó, entre mayo y junio de ese año, más de quinientos mil trabajadores urbanos.

Los grandes aportes del MNU consistieron, en esa época, en denunciar abiertamente que el mestizaje era un proyecto asimilacionista que continuaba alentando la idea del blanqueamiento de la población negra e indígena del país. Al tiempo que manifestó su oposición a la homogeneización cultural, lingüística y religiosa que desconocía las diversas cosmovisiones y aportaciones de otros segmentos de la población que no se ajustaban al patrón del monoculturalismo eurocéntrico.

Las divergencias con el MNU y otras organizaciones negras radicó en que para el primero, el problema del racismo era consecuencia del desarrollo capitalista, por lo que el principal objetivo era la instauración del socialismo, aunado a que la forma más efectiva de hacer política era mediante la lectura de las teorías revolucionarias y la organización del movimiento en núcleos revolucionarios (Sousa Junior, 2007: 79).

El MNU no consiguió aglutinar a todas las organizaciones negras del país. La multiplicidad de proyectos, estrategias y objetivos, muchas veces contrapuestos, mostró una vez más la heterogeneidad del movimiento negro. Aunado a lo anterior, los escasos recursos materiales han dificultado la implementación de proyectos.

Sin embargo, lo que sí logró el MNU fue convencer a la izquierda, que durante muchos años sólo se enfocó en la noción de clase y que responsabilizaba al movimiento negro de dividir a los trabajadores, que en Brasil existe una singularidad referente al problema de discriminación racial y, en consecuencia, la importancia y peso político del movimiento negro. A lo anterior hay que agregar que el MNU despertó a muchos afrobrasileños en todo el país, quienes buscaron organizarse, registrando un elevado número de entidades afrobrasileñas, así como de publicaciones enfocadas a discutir el problema racial en Brasil. 


\section{CONCLUSIONES}

La vanagloriada imagen de la democracia racial en Brasil logró sobrevivir durante décadas a pesar de ser cuestionada tanto en el interior como desde el ámbito externo debido a que ésta fue incentivada y difundida desde las más altas cúpulas de poder en Brasil con propósitos de política internacional.

De tal manera que, gracias a diversos documentos, fue posible demostrar que la élite brasileña, a pesar de menospreciar la rica herencia cultural africana, no sólo buscó apropiarse de tales elementos, sino que se refirió a su propia sociedad como el modelo de convivencia racial y referencia para el resto del mundo cuando su pragmática política exterior así lo requirió. Pragmatismo que tenía como propósito ser el enlace entre los recién independientes países africanos y los países occidentales en un mundo bipolar, permitiéndole abrir nuevamente su espacio geopolítico hacia el Atlántico Sur con los consecuentes beneficios que esto le proporcionaría.

Interesante el hecho que aun cuando tanto en el interior como desde el ámbito externo se denunció la situación de discriminación y desigualdad en la que vivían los negros en Brasil, la élite brasileña continuó no sólo defendiendo la idea de la democracia racial, sino que incluso llegó a considerarla como parte de los elementos que componían su seguridad nacional. Lo anterior bloqueaba cualquier intento de debate en torno del racismo al tiempo que los negros en Brasil continuaban siendo objeto de discriminación y exclusión.

Sin embargo, y a pesar de la fuerte embestida de la élite brasileña que supervaloró un modelo europeizado, homogéneo y monocultural por encima y en contra de una nación brasileña que en sus raíces estaba conformada por una multiplicidad de identidades y, después, se inclinó en defender su posición y pragmatismo a escala internacional en detrimento de la construcción de una real democracia racial, el grupo discriminado buscó de diferentes formas, con diversos grados de intensidad y múltiples matices, reivindicar sus derechos como ciudadanos brasileños, abriendo diversos espacios para revelar su inconformidad, desde organizaciones académicas, militantes, recreativas y religiosas. Considero de gran valor el hecho de que los negros aprovecharon los mismos espacios creados y alentados por el Estado que en un principio tuvieron como propósito la folclorización de sus símbolos culturales, para convertirlos en espacios de 
lucha y reivindicación, dando muestra de una gran imaginación política para enfrentarse a la exclusión y marginalización.

BiBLIOGRAFÍA

LIBROS

ADORNO, T. (2011); Indústria Cultural e sociedade. São Paulo: Paz e Terra.

ALBERTI, V. Y A. ARAUJO (2007); Histórias do movimento negro no Brasil. Depoimentos ao CPDOC. Rio de Janeiro: Pallas-CPDOC-FGV.

ALBUQUERQUE E SILVA, S.J. (2008); Combate ao Racismo. Brasília: Fundação Alexandre de Gusmão.

ALVES PENHA, E. (2011); Relações Brasil-África e geopolítica do Atlântico Sul. Salvador: Edufba.

COSTA PINTO, L.A. (1998); O negro no Rio de Janeiro. Relações de raça numa sociedade em mudança. Rio de Janeiro: UFRJ.

CYPRIANO, A., R. DE ALMEIDA Y L. PIMENTA (2009); Capoeira. Luta, Dança e Jogo de Liberdade. São Paulo: Aori.

DA COSTA FRANCO, A. [org.] (2007); Documentos da Política Externa Independente, vol.: 1. Brasília: Fundação Alexandre de Gusmão-Centro de História e Documentação Diplomática.

DA SILVEIRA, R. (2010); O Candomblé da Barroquinha. Processo de constituição do primeiro terreiro baiano de keto. Salvador: Ediciones Maianga.

DE LA SERNA, J.M. (1999); Los afronorteamericanos (Historia y destino). México: Instituto de Investigaciones Dr. José María Luis Mora.

DE SEIXAS CORRÊA, L.F. [org.] (2007); O Brasil nas Nações Unidas 1946-2006. Brasília: Fundação Alexandre de Gusmão.

DE SOUSA JUNIOR, W.A. (2007); O Ilê Aiyê e a relação com o Estado: interfaces e ambiguidades entre poder e cultura na Bahia. Salvador: Fundação de Amparo à pesquisa do Estado da Bahia, Visual Editora y Gráfica Rápida LTDA.

DOS SANTOS, J.R. Y W. DO NASCIMENTO BARBOSA (1994); Atrás do muro da noite. Dinâmica das culturas afro brasileiras. Brasília: Ministério de Cultura-Fundação Cultural Palmares. Biblioteca Palmares.

FREYRE, G. (2004); Ordem e Progresso. São Paulo: Global Editora.

, (2006); Sobrados e mucambos. Decadência do patriarcado rural e desenvolvimento do urbano. Edición Conmemorativa 70 años. São Paulo: Global Editora. 
GIMENEZ, G. (2009); Identidades sociales. México: Conaculta-Instituto Mexiquense de Cultura.

GIUCCI, G., E. RODRIGUEZ LARRETA Y E. NERY [coord.] (2002); Casa Grande \& Senzala. Gilberto Freyre: edición crítica. Francia [se utiliza la ciudad de publicación, no el país, verificar con el autor]: Allca XX.

HANCHARD, M.G. (2001); Orfeu e o poder. Movimento negro no Rio e São Paulo. Rio de Janeiro: UERJ.

HONÓRIO RODRIGUES, J. (1961); Brasil e África: Outro Horizonte. Rio de Janeiro: Editora Civilização Brasileira.

LIPPI OLIVEIRA, L. (2008); Cultura é Patrimônio. Um Guia. Rio de Janeiro: Fundação Getúlio Vargas.

MOVIMENTO NEGRO UNIFICADO (1988); 1978-1988. 10 anos de luta contra o racismo. São Paulo: Cofraria do Livro.

NASCIMENTO, A. [org.] (1982); O Negro Revoltado. Rio de Janeiro: Nova Fronteira.

SOUZA CAMPOS DE MORAES LEME, R. (2001); Absurdos e milagres: Um estudo sobre a política externa do Lusotropicalismo (1930-1960). Brasília: Fundação Alexandre de Gusmão.

SOUZA, D. (1965); África difícil: missão condenada (diário). Rio de Janeiro: Editora Leitura.

SPEKTOR, M. [org.] (2010); Azeredo da Silveira. Um depoimento. Rio de Janeiro: Fundación Getúlio Vargas.

TELES DOS SANTOS, J. (2005); O poder da cultura e a cultura no poder. Salvador: Edufba.

WAISELFISZ, J.J. (2012); Mapa da Violência 2012. A cor dos homicídios no Brasil. Brasília: Cabela-FLACSO-Brasil-Seppir, Governo do Brasil.

\section{ARTÍ́CULOS DE REVISTAS}

ALBERTO, P.L. (2011); "Para africano ver: Intecâmbios africano-baianos na reinvenção da democracia racial, 1961-1963”, en Afro-Ásia, 44, pp. 97-150.

FREYRE, G. (1961); “O Brasil, líder da civilização tropical”, en O Cruzeiro, en la Biblioteca Virtual Gilberto Freyre, en: http://bvgf.fgf.org.br/portugues/ obra/artigos_imprensa/brasil_lider.html.

, (1961); “O Brasil, mediador entre a Europa e o Trópico”, en O Cruzeiro, en la Biblioteca Virtual Gilberto Freyre, http://bvgf.fgf.org.br/portugues/obra/artigos_imprensa/brasil_mediador.html

COSTA, H. (1948); “Queremos estudar”, en Quilombo. Vida, problemas e aspirações do negro, $1, \mathrm{p} .4$. 


\section{ARCHIVOS CONSULTADOS}

Archivo CPDoc-Fundación Getúlio Vargas. Archivo Antônio Azeredo da Silveira. Archivo Histórico de Itamaraty-Rio de Janeiro. Archivos Particulares Afonso Arinos.

\section{DOCUMENTAL}

Luiz Felipe Goulart, Mestre Bimba. O Rei da Capoeira, Salvador, Fundação Mestre Bimba, 2007. 